\title{
Corpus do conhecimento em educação especial: discursos e acontecimentos
}

\author{
Antônio Carlos do Nascimento Osório*
}

\section{Resumo}

Este artigo trata de reflexões sobre a disciplina Educação, na temática Educação Especial - Inclusão Escolar, tendo como subsídios teóricos e metodológicos parte dos escritos nos referenciais de Michel Foucault, dando conotação, ao itinerário em torno de subsídios sobre as relaçôes entre saber e poder em suas complexidades e diferentes dimensões. As abrangências de cada disciplina vinculam-se de acordo com a forma e as dimensóes de interesses de um ou mais grupos de pesquisadores, buscando entrelaçamentos de linguagens; as expressóes utilizadas que constituem glossários prototípicos e ferramentas de proposiçôes, refletindo compreensōes das teorias e dos pressupostos filosóficos, salvaguardados por metalinguagens, entre seus temas, temática/conteúdos, objetos e sujeitos, representando outras relaçôes de saberes. Por intermédio de consulta eletrônica, no Banco de Teses, alojado no portal da Coordenadoria Aperfeiçoamento do Pessoal do Ensino Superior (CAPES), possibilitou um delineando do corpus, compreendido como uma coletânea de textos naturais (naturally occurring), autênticos e disponíveis, permitindo aproximações de um estado ou identificação de uma variedade de linguagens. Posteriormente, foram utilizados relatórios de dissertaçóes e teses, da mesma temática, disponibilizados, também eletronicamente por oito programas de pós-graduação em Educação. A definição dessas escolhas de cunho metodológico permite traçar algumas pistas sobre o andamento das condições a que o tema/conteúdo Educação Especial vem sendo submetida às concepções de inclusão escolar, marcadas pelas lutas, pelos confrontos, pelos comportamentos, decisôes e estratégias, assumindo características de peculiaridades sobre as observaçôes relacionadas à produção de discursos técnicos e dos seus resultados, nas relaçôes inerentes ao paradoxo, demarcando especificidades.

Palavras-chave: Educação especial; Inclusão escolar; Corpus de conhecimentos.

\footnotetext{
* Professor doutor da Universidade Federal de Mato Grosso do Sul, Campo Grande, Mato Grosso do Sul, Brasil.
} 


\section{The body of knowledge in special education: discourses and events}

\section{Abstract}

This article deals with reflections on the discipline of Education within the theme of Special Education - Inclusive Schooling, having for its theoretical and methodological subsidies part of the writings referenced in Michel Foucault, giving meaning to the itinerary to the subsidies around the relations between knowledge and power in their complexities and different dimensions. The dimensions of each discipline were linked according to the form and dimensions of the interests of one or more groups of researchers, in search of the interlacing of languages, expressions used, constituting prototype glossaries and propositional tools, reflecting comprehensions of philosophical theories and propositions saved by metalanguages, among their themes, thematical contents, objects and subjects. Using electronic consultation of the Bank of theses held online at the CAPES [Coordenadoria Aperfeiçoamento do Pessoal do Ensino Superior (CAPES)], thus permitting the delimiting of the corpus understood as a collection of naturally occurring texts, true and disposable, permitting approximations of a state or the identification of a variety of languages. Posteriorly, dissertation and thesis reports on the same theme, also electronically available in eight post-graduate programs in education. The definition of these choices of a methodological nature permits tracing some paths on the pursuit of the conditions under which the theme of Special Education has been treated through the conceptions of inclusive schooling marked by struggles, confrontations, behaviors, decisions and strategies, assuming characteristics of the peculiarities of the observations related to the production of technical discourses and of their results, in the relations inherent to the paradox, parking specificities.

Keywords: Special education; Inclusive schooling; Corpus of knowledge.

\section{Corpus do conhecimento em educação especial: discursos e acontecimentos}

A imprecisão do que poderia ser compreendido como educação, marcada pela falta de uma especificidade e pelo alargamento de suas responsabilidades sociais, veem cada vez mais, criando um movimento que pudesse delimitar seus sentidos e significados, numa sociedade que assim se intitula, como democrática e participativa, compondo direitos e respeito às diferenças, impondo diferentes discursos sobre a diversidade social.

A ausência de molduras daquilo que poderia assim chamar de educação, é indiscutível que ela é uma realidade institucional, administrativa e organizacional, infiltrada por um conjunto de práticas pedagógicas, que quando agregados professores e alunos, denomina-se de escolarização, desprovida, muitas vezes, de uma base epistemológica, que dê conta de lidar com aprendizagem, objetivos, conteúdos, métodos e avaliação, reduzindo tudo há técnicas e procedimentos, como um exame permanente e inesgotável de controle daquilo que se compreende como conhecimento. 
Isso tudo ganha corpo e outros significados quando projetado no formato organizativo dos níveis da educação e pelas modalidades de ensino, como educação infantil, educação básica e superior, que se redistribuem em outras especificidades em seu interior, além das modalidades de educação especial, de jovens e adultos, indígena e profissional.

Abarcadas pelas políticas educacionais vigentes, trazem em comum, discursos que reforçam a ausência de um projeto educacional para o Estado brasileiro, ficando as intervençôes do mesmo, reduzidas aos interesses dos partidos que tentam concentrar um determinado poder, quando anunciam algumas estratégias de governamentalidade, como direito à educação e diversidade social, tendo em comum, o paradoxo da inclusão escolar.

Este artigo surge nessa brecha, que movimentos foram se configurando nos últimos anos sobre os discursos da inclusão escolar, na produção científica, que em uma análise preliminar aponta para variaçóes significativas de compreensão, sobretudo se transformados em análises dos níveis de educação ou modalidades de ensino, transformados em campos de disputas acirradas, não só pela quantidade de estudos, mas pela diversidade de objetos e modos de apropriação, criando aspectos que a princípio, parecem não se esgotar em particularidades.

É uma espécie de tensão inesgotável, colocar em pauta a Educação, quando alinhavada a inclusão escolar, ganhando particularidades e reproduzindo especificidades de toda ordem, gerando outras dimensóes e complexidades, ao ser pontuada a luz de métodos e técnicas de pesquisa, pelos vários entrecruzamentos que ocorrem entre as teorias e pressupostos filosóficos, quando explicitados. Essas e outras questóes criam evidências inerentes às dificuldades de um estudo que dê conta de analisar a produção científica de uma determinada disciplina.

As abrangências de cada disciplina e de cada área vinculam-se de acordo com a forma e as dimensóes de interesses de um ou mais grupos de pesquisadores, buscando entrelaçamentos de linguagens; as expressôes utilizadas constituem glossários prototípicos e ferramentas de proposiçóes, refletindo compreensóes das teorias e dos pressupostos filosóficos, salvaguardados por metalinguagens, entre seus temas, temática, objetos e sujeitos, representando outras relaçóes de saberes.

Para analise dos resultados garimpados, procede-se uma articulaçáo com alguns referenciais de Michel Foucault e analisam-se subsídios que permitem traçar um panorama preliminar sobre as tendências da produção científica na disciplina de Educação, no tema Educação Especial. Nada muito fácil, nada tão simples, mas algo que pode ser transgredido. Esse olhar se tornou possível também pelas discussões acumuladas nas últimas décadas, no Grupo de Estudos e Investigaçóes Acadêmicas nos Referenciais Foucaultianos (GEIARF) sobre as formas de apropriação e das possibilidades fornecidas, por este autor, para a construção do conhecimento.

Como base empírica, forma realizadas consultas eletrônicas e inventários cuja maior concentração encontrou-se no Banco de Teses, alojado no portal da Coordenadoria Aperfeiçoamento do Pessoal do Ensino Superior (CAPES). O corpus, nessas 
consultas, constituiu-se de título, resumo e palavras-chave. Além dessa fonte, também foram utilizados relatórios de dissertaçôes e teses do tema/conteúdo Educação Especial - Inclusão Escolar, disponibilizadas por oito programas de pós-graduação em Educação, compreendido como uma coletânea de textos naturais (naturally occurring), autênticos e disponíveis, permitindo aproximaçóes de um estado ou identificação de uma variedade de linguagens, enquanto um procedimento bastante utilizado em pesquisas da área de linguística, que sempre ocorrem por amostragem, não sendo, entretanto, o caso dos inventários realizados. (SINCLAIR, 1991).

A definição dessas escolhas de cunho metodológico permite traçar algumas pistas sobre o andamento das condiçôes a que o tema Educação Especial vem sendo submetido, em relação às questóes inicialmente apontadas neste texto - inclusão escolar. Essas questôes devem ser analisadas pelas lutas, pelos confrontos, pelos comportamentos, decisóes e estratégias, assumindo características de peculiaridades sobre as observaçóes relacionadas à produção de discursos técnicos e dos seus resultados, nas relaçôes inerentes ao tema. Seja na condição de disciplina (Educação) ou na de um tema pertinente a ela (Educação Especial), haverá especificidades próprias em cada nível de relação, além daqueles já colocados.

Em um recorte desses aspectos multidimensionais e na mesma direção, Foucault (1978, p.16) traz a explicação do que seria uma disciplina e como se estabelece, "na medida em que há uma multiplicidade e um fim, ou um objetivo, ou um resultado a obter a partir sua multiplicidade". Cita um conjunto de especificidades, entre elas as disciplinas relacionadas à escola, aos militares, ao sistema penal e às fábricas, reforçando que tudo isso se adequa às exigências e determinaçóes como "uma maneira de administrar a multiplicidade, de organizá-la, de estabelecer seus pontos de implantação, as coordenaçôes, as trajetórias laterais ou horizontais, as trajetórias verticais e piramidais, à hierarquia”.

Na mesma obra Foucault (1978, p. 17) pontua, ainda, que a disciplina se estrutura por intermédio de cada indivíduo, a partir das determinaçóes das práticas culturais, suas regras, suas crenças e seus valores, pois "o indivíduo é muito mais uma determinada maneira de recortar a multiplicidade do que a matéria-prima a partir da qual ela é construída", como um modo "de individualização das multiplicidades, e não algo que, a partir dos indivíduos trabalhados primeiramente a título individual, construiria em seguida uma espécie de edifício de elementos múltiplos" e conclui: "afinal, a soberania, a disciplina, como também, é claro, a segurança só podem lidar com multiplicidades".

Embora demarcados os elos e suas condiçôes de ocorrências, a subjetivação de cada um dos modos de perceber a disciplina de educação e suas possibilidades, reforça o princípio da multiplicidade, que, mesmo assim, dá possibilidades para constituição de unidade ou não em suas diferentes compreensóes. Isso, na medida do possível, garante as condiçóes de como ocorreu sua formaçáo e seu objeto de conhecimento, sendo-lhe atribuídas determinadas valorizaçóes, muitas vezes superiores ao momento em que se encontra. 
Nesse sentido, o importante é compreender essas multiplicidades pelos seus movimentos, porém, sem adentrar ao mérito de suas validades, no caso, a Educação Especial - Inclusão Escolar. Indiscutivelmente, são os registros de suas formas de segurança e de espaços. Não há abertura para sua negação, mas evidências de predisposiçóes, em cada parte de sua história, desde o seu surgimento até a atualidade.

Ao discorrer sobre essas condições que não se esgotam, parto, nesta reflexão, de dois argumentos sobre a utilização do referencial de Foucault (2001). O primeiro refere-se à concepção de pesquisa na área das ciências do homem: "As palavras e as coisas: uma arqueologia das ciências humanas". O saber surge pelas práticas discursivas, por diálogos variados entre o pesquisador e as coisas pesquisadas, seja por intermédio das teorias, objetos ou sujeitos, assim selecionados, numa manutenção de estratégias determinadas de governamentalidade, em que cada um concebe o conhecimento em sua multiplicidade, pelos espaços em que estão instituídas suas práticas culturais e sua vinculação a diferentes grupos e áreas de saberes.

O segundo argumento é sobre a formulação e a manutenção sobre Educação Especial, inserida, neste contexto, como um dos temas da área de Educaçáo, que transita pelas possíveis interfaces com outras disciplinas, entre elas, a Psicologia, a Filosofia, a Saúde, Política e a Sociologia, ou entre seus conteúdos, alinhando-se e dando sentidos e significados na produçáo de seus artefatos, que são repertórios marcados por graus variados de especificidades, constituindo-se em um mosaico, como a demarca a Educação, enquanto espaço e tempo.

Esses dois destaques, previamente colocadas, deram origem ao seguinte princípio: de que o universo da Educação Especial a ser analisado neste texto segue com o propósito de identificar, na medida do possível, as tendências da sua produçáo científica, lidando com informaçóes e recorrendo aos subsídios que possibilitem acompanhar as transformaçóes históricas ocorridas, encaradas a partir da multiplicidade de temáticas/objetos que a caracterizam, inseridos na disciplina de Educação.

A Educação Especial, na condição de um tema da disciplina Educação e pelas condiçóes de "um ramo de conhecimento", agrega teorias e epistemologias de diferentes áreas de saberes, que se agrupam e a caracterizam. Lida com sistema cumulativo de subsídios, permitindo separar, ordenar e classificar, em diferentes graus de homogeneidade temática, marcadas por tentativas de normalização, tendo como referência a grande área de saber e seus diálogos constantes com outras disciplinas.

Pelo conjunto de suas produções, a Educação Especial dá corpo às representações, no sentido em que lhe é concedida, pelas particularidades de suas problematizações, pelos seus objetos, sujeitos envolvidos e métodos, e, ainda, pelas possibilidades de agrupamentos desses saberes em unidades específicas (temas), que ainda podem ser redistribuídos em seu interior em conteúdos (temáticas), dando um caráter local da produção. (FOUCAULT, 1997).

Por último, a governamentalidade, emprestada do mesmo autor como aporte metodológico, neste texto, enquanto práticas de gestão governamental, que tem como objetivo central o controle de populaçóes e se fundamentam no saber da eco- 
nomia e nos dispositivos de segurança, como seus mecanismos básicos de sustentação. Foucault (1994) também a considera como o encontro entre as técnicas de dominação exercidas sobre os outros e sobre nós mesmos, pois nada mais é uma maneira individual de recortar um tema/temática, do que explicar como foi pensada.

No caso da Educação Especial, como um dos temas da disciplina de Educação, essas compreensôes aumentam e se ramificam por diferentes ordens. Em estudos realizados pelo GEIARF, na fase de elaboração do estado do conhecimento e da arte dos pós-graduandos para identificar em que medida a proposta de trabalho, ainda em um roteiro genérico das intençóes investigativas, pode se transformar em um problema de estudo e quais indagaçóes devem ser formuladas sinalizando indicativos de relevâncias de propósitos, conseguiu-se a identificaçấo de uma variedade de aproximaçóes e concepçóes.

Enquanto um rastreamento, essa etapa, fundamental e inicial, pode ser evidenciada nos relatórios de dissertaçôes e teses, exclusivamente tendo em pauta a Educação Especial, Guimarães (2005; 2012), Bruno (2006), Santos (2007; 2011) e Alves (2008), quando adotaram, como uma das fontes de consulta, o Banco de Teses da CAPES, a fim de identificarem, a partir da leitura dos resumos, quais os relatórios deveriam ser selecionados para uma leitura integral, de forma a dar contribuiçóes para definição de seus interesses e delimitaçóes de seus estudos e, ao mesmo tempo, conseguir o diferencial do ineditismo em sua pretensão investigativa.

Essa possibilidade tem se configurado, pela estatística, no que Foucault (1994, p. 365) considera "conhecimento do Estado, conhecimento das forças e dos recursos que caracterizam um Estado em um momento dado". O autor cita, entre os exemplos: "o conhecimento da populaçáo, medida de sua quantidade (...) estimativa das riquezas que circulam (...) são todos esses dados e muitos outros que vão constituir agora o conteúdo essencial do saber do soberano", e complementa: "Não mais, portanto, corpus de lei ou habilidade em aplicá-las quando necessário, mas o conjunto de conhecimento técnico que caracterizam a realidade do próprio Estado". É, enquanto uma realidade que se busca, a Educação Especial.

Como ferramenta, a estatística transformou-se determinante, associada aos recursos computacionais de coleta de subsídios para confecção de inventários, contribuindo para o atendimento do objetivo proposto deste texto. A primeira tentativa foi estabelecer os critérios de consultas a partir da configuração do Banco de Teses da CAPES. Esse processo exigiu várias leituras das informaçōes disponibilizadas, constando que a catalogação dos relatórios ocorre por ano, no período compreendido de 1987 a 2011, com finalização de consulta em outubro de 2012. O método permitiu agrupar e estabelecer intervalos e probabilidades, lidando com seus resultados por intermédio de números e porcentagens e, ainda, realizando cruzamentos dessas informaçôes, dando origem a outras relaçóes.

$\mathrm{Na}$ identificação dos elementos estruturais em relação aos aspectos gerais de organização do Banco de Dados, constatou-se uma variação do vocabulário utilizado pelos autores, na totalidade do corpus. Os significados eram semelhantes (sinônimos), 
nos títulos, nos resumos e nas palavras-chave. Optou-se por transcrever esse vocabulário, tentando identificar suas respectivas aproximaçôes. Foi o início de elaboração do glossário. Durante esse processo de consulta eletrônica, ainda, explicitaram-se elementos relacionados à qualidade das informaçóes disponíveis e os riscos de se ater aos resumos disponíveis, reforçando a ideia de que estes servem como um dos critérios iniciais de seleção de futuras leituras dos relatórios completos, como foi realizado no segundo momento.

A opção pela elaboração de um glossário do vocabulário empregado ocorreu, exatamente, pelas condiçóes do que estava disponível, como parte dos resultados dos mapeamentos dessas expressóes, tomando-se o cuidado, também, de registrar o número de ocorrências. A maior incidência ocorreu com o termo Educação Especial, indicando a necessidade de transformá-la em expressão diversa dos demais descritores, para a realização de futuras consultas, com variantes relacionais, na tentativa de captar as diferentes formas de manifestação dos aspectos registrados sobre o tema.

Para o tratamento dessas informações, no final da elaboração do glossário, foram de utilizados recursos computacionais, visando a estabelecer projeçôes de médias simples. Isso não ocorreu de uma forma tranquila, por conta da variação das expressões encontradas e de suas associaçôes, além da abertura, esse vocabulário possibilitava outros significados, exigindo novas leituras.

Vejam-se os exemplos a seguir: a expressão deficiência continha uma variação, pela associação de palavras, como educação especial e deficiência, deficiência e portador de deficiência; deficiência auditiva - surdo e surdez; deficiência visual - cego e cegueira; deficiente e deficiência; deficiência mental e intelectual, deficiência e inclusão. Nessa situação, o que poderá ser observado, posteriormente, nos resultados das análises, a marcação ocorreu pelo glossário em sua somatória, a partir da aferição em cada variação e pela somatória das ocorrências, buscando a totalidade das produçóes sobre deficiência.

As evidências parciais (unidades, semelhanças ou sinônimos), em cada uma das associaçôes de palavras com a expressão deficiência, propiciaram outros índices que foram agrupados, embora, em muitos casos, tenham aparecido como sinônimo, conforme pode-se observar, com a expressão inclusão.

Para esse vocábulo aparecem expressōes como: educação especial e inclusão escolar; inclusão e educação inclusiva; inclusão escolar; inclusão social; inclusão e integração; necessidades especiais e inclusão; inclusão e trabalho; inclusão e mercado de trabalho; inclusão em classes escolar; políticas de inclusão; inclusão e portador de deficiência; inclusão e deficiência: (auditiva, surdo e surdez) e ensino de LIBRAS (cego e cegueira), (mental/intelectual) e (altas habilidades e superdotação); inserção social e deficiência; deficiência e mercado de trabalho, além de outras associações, entre elas, os vocabulários exclusão social, ensino, atendimento e família. Todas foram localizadas por meio da expressão inclusão, independentemente de sua categorização.

Essas constataçôes decorrentes das primeiras leituras e as consultas para seleção das produções pelo descritor "Educação Especial" permitiram identificar redes 
de concepçóes sobre a mesma, manifestadas por intermédio das especificidades da disciplina de Educação e seus respectivos temas. Essa confirmação ocorreu na utilização deste descritor enunciado pela totalidade de produçóes disponíveis no Banco de Dados da CAPES, em 7.754 produçôes, sendo 6.136 de dissertaçôes e 1.518 de teses.

A Educação Especial se revelou de forma polifuncional como um tema da disciplina de Educação, calcada em temáticas por constantes variações, embora em diálogos específicos, dimensionando multiplicidades de sua compreensão e permitindo, pelo glossário de vocabulários, observar diferentes agrupamentos de estudos. Sáo redes de concepçóes tanto de uma ou de mais teorias no mesmo relatório, como do mesmo tema. A diferença se estabelece na localização das produçôes em suas especificidades, em primeiro plano.

O que pode ser observado é que a definição dos temas ocorre por duas vertentes, mais voltadas à forma de organizaçáo dos cursos de pós-graduações, em linhas de pesquisa, sustentadas pelos grupos de estudos e pela disponibilidade de vagas. Por outro lado, as linhas de pesquisas, numa consulta prévia às páginas dos programas de pós-graduação, estruturam-se em um ou mais temas da disciplina Educação, associadamente ou não a outras disciplinas da área ou a outras áreas, ocorrendo semelhanças com os grupos de estudos. Poucos são aqueles que se organizam a partir de um determinado referencial teórico.

O que ficou explícito, durante essa consulta, foi um conjunto de particularidades que, embora anuncie o tema Educação Especial localizada na disciplina Educação, seus registros constam de interfaces, de forma direta ou indireta, com outros temas e disciplinas no mesmo campo de saber ou com outras disciplinas de diferentes áreas de conhecimento, herdando as próprias características da Educação.

Isso permite afirmar que o tema Educação Especial reproduz parte dos elementos já comentados neste texto, entre eles conceitos variados, leituras diferenciadas das mesmas obras, olhares diferenciados dos mesmos objetos na utilização ou não de elementos da sociologia, filosofia e psicologia, principalmente, podendo ser compreendidos este movimento como estratégia "capaz de afrontar a complexidade e as contradiçóes características da contemporaneidade”. (CHARLOT, 2006, p. 6).

A maior concentração dos resultados, $63 \%$, contém o movimento da produção científica pela disciplina de Educação, associada às características da clientela, tendo, como focos entre eles, interfaces com a educação de jovens e adultos, educação indígena, educação no campo, educação ribeirinha, educação em assentamentos, educação para o trabalhador, educação profissional, qualificação profissional de trabalhadores; formação de professores, alfabetização, programas e políticas de estado (gestão, avaliação, financiamento, legislação; classes de educaçáo especial, classes multifuncional, diversidade, direito, minorias sociais entre outros), além de se relacionarem às questôes de gênero, raça ou regiāo, homofobia, falta de saúde, saúde e violência.

Concomitantemente, foi possível observar uma forte tendência dessas temáticas, associadas ou não, estarem agrupadas em fases ou etapas de escolarização, criando 
suas ocorrências pelos níveis da educação básica ou modalidades de ensino, como educação especial e educação de jovens e adultos, ou, ainda, alfabetização nos anos iniciais do ensino fundamental para deficiência mental.

Essas constatações exigiram um direcionamento para futuras consultas, impondo a necessidade de um discernimento sobre qual Educação Especial se buscava analisar, no conjunto de produções científicas que pudessem delimitar temáticas de estudos e, ao mesmo tempo, que garantissem todas as características multifuncionais possíveis, relacionadas a inclusão escolar. A referência mais próxima ocorreu pela associação do tema/temáticas, preservando-se algumas características das disciplinas da grande área.

A delimitação da temática Educação Especial se fez por ser uma das modalidades de ensino, inserida na educação escolar, prevista nos aparatos regulatórios vigentes, que deve garantir o atendimento educacional especializado, a partir de um projeto político pedagógico que assegure recursos e serviços, quando necessários, para apoiar os processos de aprendizagem, pelas demandas individuais de cada aprendiz. Entende-se, também, que tudo isso vem acontecendo de forma a preservar a concepção de direitos humanos, da igualdade de oportunidades, o reconhecimento e o respeito pelas diferenças sociais, culturais, étnicas, raciais, sexuais, físicas, intelectuais, emocionais, linguísticas entre outras, conforme documento orientador da Política Nacional de Educação Especial, na perspectiva da inclusão escolar (2008).

Essa seleção prévia para consulta ao Banco de Dados/CAPES exigiu que se agregasse, ao primeiro descritor Educação Especial, as expressôes "Deficiência" e "Superdotação/Altas habilidades", como comandos para novos rastreamentos de elaboração do inventário. O resultado das análises indicou uma redução de $85,5 \%$ das produçóes captadas nas primeiras consultas, que foi de 7.754 , passando, então, para 1.127 .

Desse total, 1.124 relacionam-se ao tema/conteúdo Educação Especial e à temática Deficiência, atendendo, desse modo, a parte do objetivo proposto neste texto. Desse número, há uma predominância de produçôes em nível de mestrado, com $81,4 \%$ de ocorrências. Chamou a atenção, o número reduzido de produçốes na unidade Superdotação/Altas Habilidades - apenas três - e sem registros em teses; conquanto se tenha conhecimento da existência desses relatórios, eles não se encontravam disponíveis no Banco de Teses, na época da consulta.

As análises apontam que, relativamente a Educação Especial, poucos são os trabalhos que não se direcionam a uma de suas temáticas tradicionais de disciplinamento pelas Deficiências mentais, visuais, auditivas, associadas ou não, e altas habilidades e/ou superdotação, além de outros estudos relacionados, tendo o apoio de algumas disciplinas da saúde, com significativas tendências às patologias, transtornos de condutas e dificuldades de aprendizagem e regras para aprendizagem.

Em relação às aplicações discursivas que remetem aos mesmos significados por semânticas diferenciadas, verificou-se que, para o primeiro descritor - deficiência - forma encontradas as expressóes: deficiência e portador de deficiência e deficiente 
e deficiência - mental e intelectual, num total de $63 \%$ das produçóes; deficiência auditiva, surdo e surdez, com $30 \%$ e, por último, com $17 \%$, deficiência visual, cego e cegueira.

Para os descritores Educação Especial e Inclusão Escolar, quando utilizados, as análises semânticas e discursivas apontam o uso das seguintes expressões: inclusão/ educação inclusiva; exclusão; necessidades especiais, de forma geral e associada à deficiência e portador de deficiência; surdo e surdez; deficiência visual, cego e cegueira; deficiência mental e intelectual e altas habilidades.

O caso das produçôes do conteúdo Inclusão Escolar ganha uma dimensão com características universalizantes, não se atendo a uma determinada condição de deficiência, observação já registrada no descritor "Educação Especial”. Além disso, tratam de similaridades entre as expressóes que se localizam na dimensão da diversidade social e do direito à educação, indicando, ainda, estudos que privilegiam as legislaçôes vigentes, programas ou políticas de Educação Especial, trazendo à tona, em alguns casos, a questáo do atendimento e das salas de recursos ou multifuncionais, sempre dependendo da temporalidade do estudo.

Relativamente à perspectiva de uma educação inclusiva, as análises refletem avanços e retrocessos das conquistas dos movimentos sociais, além dos estudos realizados na pós-graduação, na superação das barreiras econômicas, sociais, culturais e pedagógicas de acesso ao saber. Em pauta acham-se elementos políticos e técnicos que visam a uma mudança radical das práticas pedagógicas historicamente instituídas pelo disciplinamento e pela seletividade.

Essas identificaçôes ocorreram em função do modelo prototípico adotado no inventário, que, inicialmente, parece ser distinto, com resultados parciais em relação ao objetivo deste texto; porém, os modos de obtenção das informaçóes, coleta, organização e processamento destas e suas possibilidades de análises permitiram "quantificar, qualificar ou ordenar entes, coleçôes, fenômenos, populaçóes de modo tal que possa concluir, deduzir ou predizer propriedades, eventos ou estados futuros". (MILONE, 2004, p. 3).

Vale destacar que, em apenas dois anos (2010 - 2011), aproximadamente $14 \%$ do total das produçóes acumulam o tema Educação Especial, sendo que destas, $10 \%$ utilizaram a expressão inclusão categorizada ou não, sendo que $18 \%$ em nível de doutorado, o que implica tê-la transformada em um problema de estudo numa outra unidade da temática. No rastreamento, a ocorrência das expressōes Educação Especial "como" Inclusão ou Educação Especial "e" Inclusão foi constatada, no inventário, com uma incidência significativa.

Isso motivou dar continuidade e aberturas de outros inventários, agrupando outros descritores para consulta: Educação Especial e Inclusão; e, Educação Especial e Inclusão Escolar, seguindo os critérios adotados, anteriormente, de consulta, agora pelos comandos "Educação e Educação Especial" e "outras disciplinas". Essas escolhas se deram em função das primeiras leituras realizadas no Banco de Teses/CAPES. 
No tema Educação Especial com a temática Inclusão foram encontrados 814 registros, sendo que 491 em cursos de mestrados, na disciplina de Educação e 323 em outras disciplinas. Em nível de doutorado teve-se acesso a 196 cadastros, sendo que o primeiro grupo foi de 105 e no segundo, 71.

Para os descritores Educação Especial e Inclusão Escolar foram encontrados 529 cadastros de produções no Banco de Teses, como relatórios de mestrados, 63\% na disciplina de Educação e no tema Educação Especial e os demais em outras disciplinas da área de conhecimento. Especificamente à produçáo nos cursos de doutorados, o número foi de 93 no tema de Educaçáo Especial e 25 nas demais disciplinas.

O cruzamento das informaçóes subsidiadas por esses descritores permite afirmar que, do total das produçóes, $82 \%$ são em nível de mestrado, com forte concentraçáo no período compreendido entre 2005 a 2011, atingindo $73 \%$, e no doutorado o índice é superior a $80 \%$. A somatória das produçôes da pós-graduação da disciplina Educação, no descritor "Educação Especial e Inclusão Escolar" e em outras disciplinas das ciências do homem, o número de cadastros atinge, na série 1987 - 2011, de 647, sendo que destes $84 \%$ é produção no tema Educação Especial.

Há um aumento significativo nas produções da Educação Especial, porém, deve ser observado com cautela, no sentido de que as condiçóes presentes da produção científica refletem processos instituídos em décadas anteriores, sobre a Educação em seu tema Educação Especial. Ambas detêm alteraçôes de suas compreensôes e seus significados, marcando movimentos de diferentes ordens.

No caso da Educação Especial pensada pelas temáticas, deficiência e altas habilidades/supertotação, observa-se um deslocamento do aspecto clínico-pedagógico e psicopedagógico, compreendidos pela anormalidade, até o direito à educação e à diversidade social marcado pelo paradoxo da inclusão.

Porém, não há uma superposição ou nulidade entre os enfoques enunciados, mas um interesse maior, na atualidade, em compreender a inclusão como uma ou mais perspectivas possíveis ou como uma questão meramente de ordem técnica em lidar com as dificuldades de aprendizagem, o que não se limita a uma determinada clientela excluída, mas, sim, as relaçóes presentes nas práticas sociais em relação à diferença.

Em termos de Estado brasileiro, além de ser signatário de um conjunto de dispositivos orientadores internacionais incorporou os princípios norteadores desses acordos em instrumentos regulatórios. Tem-se a Lei de Diretrizes e Bases da Educação Nacional No 9394/96 e o documento orientador da Política Nacional de Educação Especial (2008), além de outros dispositivos que tentam dar uma regularização mínima, em níveis nacional e local. Esses documentos trazem, em suas bases, o modelo econômico globalizado, instaurados no final dos anos 1970, com forte expressão na década de 1990, chegando a uma ordem de acontecimento, a partir de 2000 até a atualidade, sublimados por outros mecanismos como diretrizes curriculares e decretos, que não superam as práticas culturais regradas por preconceito em relação à compreensão das temáticas relacionadas à Educação Especial. 
Encaminha-se, assim, às brechas possíveis para tentar compreender as dinâmicas das práticas culturais, nas determinaçôes sobre deficiência ou superdotação/altas habilidades, e da própria temática Educação Especial - Inclusão Escolar, fruto de regramentos entre o saber e o poder, cujas problematizaçóes se alojam em determinado grupo de sujeitos, a partir de um conjunto de tensóes, nas formas constituintes dos artefatos que envolvem anormalidades ou desajustes.

Essas proposiçôes ganham especificidades nos estudos referentes ao tema Educação Especial, pelas formas de apropriaçóes e análises, evidenciando o esforço realizado e sua evolução enquanto parte da disciplina Educação, na compreensão de suas temáticas iniciais a deficiência e a altas habilidades/superdotação com diferentes interfaces com outras disciplinas, quando lida com a inclusão escolar.

Dessas aproximaçóes surge um conjunto de práticas culturais fomentadas pelas discursivas e não discursivas (materiais) sobre o homem e, em relação à Educação Especial, permite que algo entre no jogo do verdadeiro e do falso, projetado por redes e interesses de várias ordens, refletindo sempre dimensóes e entrecruzamentos entre pontos próximos ou extremos, em que, num movimento inicial, aparentemente não estabelecem vínculos, mas, com o tempo, explicitam relaçóes com características de unidade, no caso, a Inclusão Escolar.

\section{Referências}

BRASIL. Politica Nacional de Educação Especial na Perspectiva da Educação Inclusiva SEEsp/ MEC. 2008. Disponível em: <www.mec.gov.br/SEESP>. Acesso em: 03 mar. 2010.

CHARLOT, B. A pesquisa educacional entre conhecimentos, políticas e práticas: especificidades e desafios de uma área de saber. Revista Brasileira de Educaçáo, v. 11, n. 31, jan./abr. 2006.

FOUCAULT, M. História da sexualidade 2: o uso dos prazeres. Rio de Janeiro: Jorge Zahar, 1994. As palavras e as coisas. [trad. Salma Tannus Muchal]. 8. Ed. São Paulo: Martins Fontes, 1999; 2001.

História da loucura na idade clássica. São Paulo: Perspectiva, 1978.

Resumo dos cursos do Collège de France (1970-1982). Rio de Janeiro: Jorge Zahar Ed., 1997.

BRASIL. Lei n. 9394 de 1996, Lei de Diretrizes e Bases da Educação Nacional (LDB), Brasília, DF, 1996.

MILONE, G. Estatística: geral e aplicada. São Paulo: Pioneiro Thomson Learing, 2004.

SINCLAIR, J. Corpus, concordance, collocation. Oxford: Orford University Press, 1991.

\section{Correspondência}

Antônio Carlos do Nascimento Osório - Universidade Federal de Mato Grosso do Sul, departamento de Educação. Cidade Universitária, campus Universitário, CEP: 79070-900 - Campo Grande, Mato Grosos do Sul, Brasil - Caixa-postal: 549 .

E-mail: antonio.osorio@ufms.br

Recebido em 15 de abril de 2015

Aprovado em 30 de junho de 2015 